AperTO - Archivio Istituzionale Open Access dell'Università di Torino

Systematic screening of Retinopathy in Diabetes (REaD project): An Italian implementation campaign

This is the author's manuscript

Original Citation:

Availability:

This version is available http://hdl.handle.net/2318/1654947

since 2017-12-19T12:27:16Z

Published version:

DOI:10.5301/ejo.5000912

Terms of use:

Open Access

Anyone can freely access the full text of works made available as "Open Access". Works made available under a Creative Commons license can be used according to the terms and conditions of said license. Use of all other works requires consent of the right holder (author or publisher) if not exempted from copyright protection by the applicable law. 


\section{Systematic screening of REtinopathy in Diabetes (REaD project): an Italian implementation campaign}

Running head: Diabetic retinopathy screening

Authors:

Massimo Porta ${ }^{1}$, Francesco Boscia ${ }^{2}$, Paolo Lanzetta ${ }^{3}$, Edoardo Mannucci $^{4}$, Ugo Menchini ${ }^{5}$, Francesca Simonelli ${ }^{6}$.

Affiliations:

${ }^{1}$ Department of Medical Sciences, University of Turin, Turin. ${ }^{2}$ Clinica Oculistica, Department of Surgical, Microsurgical and Medical Sciences. University of Sassari. Sassari. ${ }^{3}$ Department of Medical and Biological Sciences -Ophthalmology. University of Udine. ${ }^{4}$ Diabetes Unit, CareggiHospital, Florence. ${ }^{5}$ CareggiUniversity Hospital, University of Florence. ${ }^{6}$ Eye Clinic, Multidisciplinary Department of Medical, Surgical and Dental Sciences,Second University of Naples, Naples.

Corresponding Author:

Prof. Massimo Porta, MD PhD

Dept. of Medical Sciences

University of Turin

Corso AM Dogliotti 14

10126 Torino

Italy

Tel. +390116336028

Email: massimo.porta@unito.it 


\begin{abstract}
Aims: To evaluate the use of telemedicine retinal screening in Italy and to identify potential elements of implementation of this system.

Methods: Patients with either new onset diabetes or no ophthalmologic visit over the previous 2 years and attending 33 referral diabetic centers between mid April 2013 and mid December 2015 were screened. Two partially overlapping non-stereoscopic $45^{\circ}$ digital color images were captured from each eye using a fully automated non-mydriatic digital fundus camera. Factors limiting the assessment of retinopathy were explored.
\end{abstract}

Results: Out of 24,473 eligible individuals, 22,466 had complete data. Among them, good-quality images enabling appropriate evaluation of at least one eye were obtained from 19,712 patients (both eyes, $\mathrm{N}=18,887$ ). Although non-mydriatic retinographs were provided, 39\% of patients were evaluated using mydriasis. The rate of low-quality images in each center was inversely associated with the number of patients assessed. This was more evident for screening in mydriasis: adjusted OR, 0.79 [95\%CI, 0.76-0.82] $(\mathrm{P}<0.001)$ vs. 0.96 [95\%CI, 0.94-0.97] $(\mathrm{P}<0.001)$. Finally, both the number of patients assessed and use of mydriasis were inversely related to the presence of DR: adjusted OR, 0.93 [95\%CI, 0.92-0.93] $(\mathrm{P}<0.001)$ and 0.88 [95\%CI, 0.82-0.96] $(\mathrm{P}<0.001)$, respectively.

Conclusions: This program confirmed a role for teleophthalmology in the systematic screening of DR and provided important suggestions to improve the system deployed. A high level of training is required for operators to optimize imaging. Besides, photographic screening should be performed in mydriasis whenever possible.

Keywords: diabetic retinopathy; diabetic macular edema; teleophthalmology; screening 


\section{Introduction}

Diabetic retinopathy (DR) is a complication of both type-1 (T1D) and type-2 diabetes (T2D) [1]. With an overall prevalence of 35\% [2] it remains the commonest cause of adult-onset blindness [35]. While appropriate glucose control has been shown to reduce its incidence and progression [6-8], timely recognition and appropriate management of DR were proven effective in preventing vision loss $[9,10]$. Therefore, systematic screening with periodic eye examination is critical for outcome improvement. Major improvements in detection and diagnostic practices have occurred over the last decades and international guidelines have been established to improve standards of care in diabetes, including those enabling the identification of early-stage DR [8,11]. Specifically, an initial dilated eye examination should be performed within 5 years after the onset of T1D diabetes, at the time of diagnosis for persons with T2D and annually thereafter [8] but adherence to guideline-based recommendations is still sub-optimal, not only in terms of control of cardiovascular risk factors $[12,13]$ but also relevant to eye care [14]. A main barrier to screening is poor accessibility to eye care specialists $[15,16]$, which is likely to worsen in the future $[17,18]$ if appropriate policies are not considered. In recent years, digital retinal photography associated with teleophthalmology has emerged as a valuable, accurate, reliable and cost effective procedure for systematic screening of DR [14,19-21]. Its mission is to “...increase access and adherence to demonstrated standards of care among individuals with diabetes mellitus ..” [21]. A large-scale campaign was carried out in Italy to evaluate the systematic use of telemedicine in retinal screening, with special attention to feasibility and identification of those factors that could help promoting its implementation in routine care.

\section{Methods}

The REtinopathy in Diabetes (REaD) project was an implementation campaign of systematic screening conducted in 33 diabetic outpatient clinics in Italy (Supplementary Appendix) between 
mid-April 2013 and mid-December 2015 as a continuing medical education (CME) project. The outpatient clinics were selected depending on the presence in the same institution of a collaborative ophthalmology unit. The initiative was carried out according to practice recommendations established by the American Telemedicine Association [21]. Diabetic patients attending the clinics with either recent onset diabetes or who had no ophthalmologic visit over the previous 2 years were considered eligible. Licensed eye care professionals - mainly nurses - were trained to use a fully automated non-mydriatic digital fundus camera (Digital Retinography System [DRS]; Centervue SpA, Padova, Italy) by technicians made available by the manufacturer. Training consisted in a 3hour theoretical and practical session. Trained operators with medical supervision were responsible for retinal imaging directly at the diabetic outpatient clinic. Technical support from the manufacturer was available upon request. The centers involved had an option to perform retinal photography in mydriasis or not, according to local practices and preferences. Two partially overlapping non-stereoscopic $45^{\circ}$ digital color images were captured from each eye and, where applicable, the operators were asked to record the possible causes of inability to collect assessable images. All retinographs were remotely reviewed by ophtalmologists for the presence and severity of DR, according to a simplified version of the American Academy of Ophthalmology classification [22]. The following conditions were considered: no apparent retinopathy (no DR), non-proliferative DR, and proliferative DR (PDR). To be graded all patients should have had at least one goodquality photo of the fundus recorded. Severity of DR was assigned according to the worst eye. Grading ophthalmologists were asked to indicate any potential explanation for inability to appropriately rate the images. Patients with unobtainable or unreadable images, as well as those with positive screening, were referred for full ophthalmological examination and follow-up, in agreement with international and national recommendations $[8,11]$.

Data on age, gender, smoking status (never/former/current), hypertension (self-report of a previous diagnosis by a clinician and/or ongoing therapy), and type of diabetes (coded as T1D or T2D or other) were also recorded. 
The program was approved by local institutional review boards and written informed consent was obtained from every patient.

\section{Statistical analysis}

Descriptive statistics were presented as mean, standard deviation (SD) and ranges or counts and percentage, as appropriate. Although images were collected by operators after an initial training, a learning curve, with improvement of screening activities/practices, was hypothesized to occur during the program and investigated accordingly. In particular, the number of patients assessed in each center was taken as a surrogate measure of increasing experience. Then, non collinear variables (checked with Pearson's statistic) associated with collection of low-quality photographs were investigated by multivariate logistic regression analysis. Interaction between covariates was also tested where appropriate. Finally, prevalence of DR was computed with 95\% confidence interval (95\%CI). Methodological factors potentially influencing the prevalence of DR were also investigated by fully-adjusted logistic regression analysis. Huber-White robust standard errors were used to account for intra-center correlation in all multivariate models.

All statistical analyses were performed using STATA 13.1 statistical software (Stata Corporation, College Station, TX, USA). The level of significance was set at two-tailed P-value $<0.05$.

\section{Results}

Over 2.5-years, 24,473 eligible patients were screened and 22,466 (males, $\mathrm{N}=12.931$ [57.6\%]) had complete demographic and clinical data (91.2\% of the initial sample) included in the final analysis. Prevalence of T1D, T2D and other types of diabetes were $12.5 \%, 87.2 \%$ and $0.5 \%$, respectively. The general characteristics of the population are shown in Table 1. Due to various reasons, images could not be obtained for both eyes and a single eye (Table 2) in 75 and 57 patients, respectively. In total 8,755 (39.1\%) patients out of 22,391 were evaluated using mydriasis. Good-quality images 
enabling appropriate evaluation of retinopathy were obtained from 19,712 patients (87.7\% of the total sample). In particular, images were available for both eyes and only one eye in 18,887 and 825 patients, respectively so that, based on the images collected, 3,447 patients had at least one eye (both eyes, $\mathrm{N}=2,679$ ) that could not be assessed. The reasons for inability to grade them - as reported by ophthalmologists - are shown in Table 2. The distribution of patients in whom images from at least one eye could not be graded is shown in Table 3, where they are grouped according to use of mydriasis and number of patients photographed in their center. Independently of use of mydriasis, higher patient throughput was associated with significant reduction of ungreadable images $(\mathrm{OR}=0.93$ [95\%CI, 0.92-0.95]; P for trend <0.001). In addition, mydriasis was less likely to result in collection of low-quality images (OR $=0.33$ [95\%CI, 0.30-0.36]; $\mathrm{P}<0.001)$. Although significant interaction between these two variables was observed, further analysis stratified by use of mydriasis showed that the latter resulted in a consistent reduction in the risk of obtaining lowquality images over time: $\mathrm{OR}=0.80$ [95\%CI, 0.77-0.83] $(\mathrm{P}<0.001)$ vs. OR $=0.97$ [95\%CI, 0.960.99] $(\mathrm{P}=0.006)$. The association with the number of patients examined remained significant (Table 4) after adjusting for age, gender, smoking status, and hypertension, regardless of mydriasis: with, $\mathrm{OR}=0.79$ [95\%CI, 0.76-0.82] (for trend, $\mathrm{P}<0.001$ ); without mydriasis, $\mathrm{OR}=0.96$ [95\%CI, 0.94-0.97] ( $\mathrm{P}$ for trend $<0.001$ ). Higher age, male gender and former/current smoking were also associated with low-quality imaging. In particular, a significant effect of age was detected for patients screened using mydriasis and aged 40 years and over.

The overall crude prevalence of any-stage DR and PDR were $16.7 \%$ and $0.7 \%$, respectively (Table 5). For patients with both eyes assessed, prevalence of bilateral any-stage DR and PDR were 14.2\% and $0.5 \%$, respectively. Finally, we observed an inverse relationship (model adjusted for age, gender, smoking status, hypertension, and type of diabetes) between DR and both increasing number of patients assessed in each center $(\mathrm{OR}=0.93$ [95\%CI, 0.92-0.93], $\mathrm{P}<0.001$; no interaction observed) and use of mydriasis (OR = 0.88 [95\%CI, 0.82-0.96], $\mathrm{P}<0.001)$. 


\section{Discussion}

As far as we are aware, this is one of the largest initiatives of DR screening and telemedicine. It was the first in Italy and, on top of improving the standards of eye care for diabetic patients, it was designed to collect information on factors potentially enabling the improvement of screening practices.

Indeed, the primary aim of screening through telehealth is to overcome limited access to licensed eye care professional $[14,21]$. This enables also to reduce the number of eye consultations and related costs. Further cost saving can be obtained by reducing the number of visits requested for failure in assessing the patients. However, telemedicine is an instrument for systematic screening of DR but cannot replace a comprehensive eye examination [21].

The feasibility of this approach and its value as a component of primary care are consistent with several previous studies $[14,19,21]$. Imaging was performed by operators who received an initial training session and, consequently, a learning curve in photography practices was observed with progressive reduction in the number of low-quality images over time. This was particularly evident for screening in mydriasis. Although retinographs have been developed to collect images in nonmydriatic conditions, it is likely that mydriasis increases the ability to collect useful photographs. Our findings are consistent with those of a recent meta-analysis on the use of telemedicine for detecting DR and reporting higher accuracy with the use of mydriasis [19]. This is relevant in clinical practice, as quality can further diminish due to pupil miosis induced by repeated flashes during the procedure. In this scenario, it was interesting to observe that mydriasis was associated not only with better screening feasibility but also lower prevalence of assessed DR. On the one hand we can speculate that lower quality images result in prudential overdiagnosis by eye specialists, while higher familiarity of graders with the program technology and high-quality images are likely to result in better screening outcomes [21]. On the other hand, it cannot be ruled out that increased burden of activities in high referral centers may result in less accurate ophthalmological assessment. Unfortunately, we were not able to further explore these hypotheses, as this program was not 
designed to address the accuracy of teleophthalmology and we did not plan for parallel systematic evaluation by eye care specialists. Indeed, more time and resources should be probably invested in the formal certification of operators training. Finally, collection of low-quality images was also associated with increasing age, male gender and smoking habits. On top of being associated with increased risk for cataract, such variables may reflect poor patient collaboration and further reduce the success rate of retinal photography. Although the association between higher age and screening failure rate supports previous reports that screening of DR in advanced age may not be costeffective [23], replacing opportunistic with systematic screening remains justified at population level [14].

With respect to prevalence of DR, we highlight that this program was not designed to provide such information and, based on design and eligibility criteria, inclusion bias was likely. It should be stressed that the sample was not representative of the whole population of patients with diabetes, and that the enrollment bias could differ across study centers. Nonetheless, it is worth mentioning that several prevalence studies have been performed [23-29] and estimates are substantially heterogeneous. Besides, the largest studies available are retrospective database analyses with methodological limitations [25-27]. As recently reviewed, heterogeneity is likely due to methodological disparities between studies in such issues as case identification, inclusion criteria (e.g. age), use of mydriasis, number of retinal fields per eye, grading protocols and definitions $[2,5,31]$. In addition, based on our results, a role for the level of imager training becomes evident. This picture clearly emphasizes that country-specific data are needed as they probably reflect ethnic differences (e.g. in body weight and/or genetics) but also heterogeneity in medical care. Updated prevalence estimates are also necessary because, despite burden projection [17], an improvement in overall medical care and diagnosis have brought to a significant reduction in complications of diabetes [2,32]. With respect to our initiative, we recognize as a limitation that it was carried out in outpatient settings in which screening of more severe cases could have been hypothesized. In Italy at least $50 \%$ of diabetic patients are exclusively managed by general practitioners [9] and the 
numbers are increasing due to changing health policies whereas the campaign was carried out at specialized high-level referral centers, in which close and effective cooperation with ophthalmologists can be established.

Points of strength should also be considered. First, this was a prospective investigation, in that it investigated the learning curves of the operators. Second, it was the first campaign designed not only to evaluate the feasibility of teleophthalmology but also to collect information on how to implement it in the clinical setting.

In conclusion, our campaign not only confirmed a role for teleophthalmology in systematic screening for DR but provided useful suggestions for improving this system. In addition to building reference diabetic retinopathy screening services, a critical factor was the level of training required for non-specialist operators. Accordingly, to optimize retinal imaging, the introduction of certification programs, quality assurance practices and evaluation of cost-effectiveness should be considered. Besides, screening in mydriasis should be considered whenever possible, even with non-mydriatic cameras.

\section{Acknowledgements}

The authors thank all the retinologists who participated to the REaD Group. Writing assistance was provided by Edra Spa. This assistance was funded by Novartis Farma SpA, Italy.

Conflict of Interest Disclosures: The Authors certify that there are no affiliations with, or involvement in, any organization or entity that has a direct financial interest in the subject matter, or material, discussed in the manuscript.

Financial disclosures: The authors have no proprietary or commercial interest regarding any of the products mentioned. 


\section{References}

1. American Diabetes Association. Diagnosis and classification of diabetes mellitus. Diabetes Care. 2014 Jan;37 Suppl 1:S81-90.

2. Yau JW, Rogers SL, Kawasaki R, Lamoureux EL, Kowalski JW, Bek T, Chen SJ, Dekker JM, Fletcher A, Grauslund J, Haffner S, Hamman RF, Ikram MK, Kayama T, Klein BE, Klein R, Krishnaiah S, Mayurasakorn K, O'Hare JP, Orchard TJ, Porta M, Rema M, Roy MS, Sharma T, Shaw J, Taylor H, Tielsch JM, Varma R, Wang JJ, Wang N, West S, Xu L, Yasuda M, Zhang X, Mitchell P, Wong TY; Meta-Analysis for Eye Disease (META-EYE) Study Group. Global prevalence and major risk factors of diabetic retinopathy. Diabetes Care. 2012 Mar;35(3):556-64.

3. National Diabetes Fact Sheet: national estimates and general information on diabetes and prediabetes in the United States, 2011. Atlanta: Department of Health and Human Services, Centers for Control and Prevention, 2011.

4. Fong DS, Aiello LP, Gardner TW, King GL, Blankenship G, Cavallerano JD, Ferris FL 3rd, Klein R; American Diabetes Association. Diabetic retinopathy. Diabetes Care. 2003;26:S99-102.

5. Klein BE. Overview of epidemiologic studies of diabetic retinopathy. Ophthalmic Epidemiol 2007;14:179-183

6. Fullerton B, Jeitler K, Seitz M, Horvath K, Berghold A, Siebenhofer A. Intensive glucose control versus conventional glucose control for type 1 diabetes mellitus. Cochrane Database Syst Rev. 2014 Feb 14;2:CD009122.

7. Hemmingsen B, Lund SS, Gluud C, Vaag A, Almdal TP, Hemmingsen C, Wetterslev J. Targeting intensive glycaemic control versus targeting conventional glycaemic control for type 2 diabetes mellitus. Cochrane Database Syst Rev. 2013 Nov 11;11:CD008143.

8. American Diabetes Association. Standards of medical care in diabetes -- 2013. Diabetes Care. 2013;36(suppl 1):S11-S66.

9. Diabetic Retinopathy Study Research Group. Photocoagulation treatment of proliferative diabetic retinopathy: the second report of diabetic retinopathy study findings. Ophthalmology 1978;85:82106.

10. Early Treatment Diabetic Retinopathy Study Research Group. Early photocoagulation for diabetic retinopathy. ETDRS report number 9. Ophthalmology 1991;98:766-85.

11. Guidelines for the Screening, Diagnosis and Treatment of Diabetic Retinopathy in Italy. Text revision - 2015. Available at: http://www.aemmedi.it/pages/linee-guida_e_raccomandazioni/

12. Brown LC, Johnson JA, Majumdar SR, Tsuyuki RT, McAlister FA. Evidence of suboptimal management of cardiovascular risk in patients with type 2 diabetes mellitus and symptomatic atherosclerosis. CMAJ.2004;171:1189-1192.

13. Coon P, Zulkowski K. Adherence to American Diabetes Association standards of care by rural health care providers. Diabetes Care. 2002;25:2224-2229 
14. Zimmer-Galler IE, Kimura AE, Gupta S. Diabetic retinopathy screening and the use of telemedicine. Curr Opin Ophthalmol. 2015 May;26(3):167-72.

15. Hazin R, Barazi MK, Summerfield $M$. Challenges to establishing nationwide diabetic retinopathy screening programs. Curr Opin Ophthalmol. 2011 May;22(3):174-9.

16. Owsley C, McGwin G Jr, Lee DJ, Lam BL, Friedman DS, Gower EW, Haller JA, Hark LA, Saaddine J; Innovative Network for Sight (INSIGHT) Research Group. Diabetes eye screening in urban settings serving minority populations: detection of diabetic retinopathy and other ocular findings using telemedicine. JAMA Ophthalmol. 2015 Feb;133(2):174-81.

17. Boyle JP, Honeycutt AA, Narayan KM, Hoerger TJ, Geiss LS, Chen H, Thompson TJ. Projection of diabetes burden through 2050: impact of changing demography and disease prevalence in the U.S. Diabetes Care. 2001 Nov;24(11):1936-40.

18. Saaddine JB, Honeycutt AA, Narayan KM, Zhang X, Klein R, Boyle JP. Projection of diabetic retinopathy and other major eye diseases among people with diabetes mellitus: United States, 20052050. Arch Ophthalmol. 2008 Dec;126(12):1740-7.

19. Shi L, Wu H, Dong J, Jiang K, Lu X, Shi J. Telemedicine for detecting diabetic retinopathy: a systematic review and meta-analysis. Br J Ophthalmol. 2015 Jun;99(6):823-31.

20. Kirkizlar E, Serban N, Sisson JA, Swann JL, Barnes CS, Williams MD. Evaluation of telemedicine for screening of diabetic retinopathy in the Veterans Health Administration. Ophthalmology. 2013;120(12):2604-2610.

21. Cavallerano J, Zimmer-Galler I, Tennant M, Abramoff M, Chaum E, Debuc DC, LeonardMartin T, Winchester M; American Telemedicine Association Diabetic Retinopathy Telehealth Practice Recommendations Working Group. Telehealth practice recommendations for diabetic retinopathy, second edition. Telemed J E Health. 2011;17(10):814-837.

22. Wilkinson CP, Ferris FL 3rd, Klein RE, Lee PP, Agardh CD, Davis M, Dills D, Kampik A, Pararajasegaram R, Verdaguer JT; Global Diabetic Retinopathy Project Group. Proposed international clinical diabetic retinopathy and diabetic macular edema disease severity scales. Ophthalmology. 2003 Sep;110(9):1677-82.

23. Tye A, Wharton H, Wright A, Yang Y, Gibson J, Syed A, Mills A, Dodson P. Evaluating digital diabetic retinopathy screening in people aged 90 years and over. Eye (Lond). 2015 Nov;29(11):1442-5.

24. Olafsdottir E, Andersson DK, Dedorsson I, Stefánsson E. The prevalence of retinopathy in subjects with and without type 2 diabetes mellitus. Acta Ophthalmol 2014;92:133-7.

25. Jee D, Lee WK, Kang S. Prevalence and risk factors for diabetic retinopathy: the Korea National Health and Nutrition Examination Survey 2008-2011. Invest Ophthalmol Vis Sci. 2013 Oct 17;54(10):6827-33.

26. Rodriguez-Poncelas A, Miravet-Jiménez S, Casellas A, Barrot-De La Puente JF, Franch-Nadal J, López-Simarro F, Mata-Cases M, Mundet-Tudurí X. Prevalence of diabetic retinopathy in individuals with type 2 diabetes who had recorded diabetic retinopathy from retinal photographs in Catalonia (Spain). Br J Ophthalmol. 2015 Jun 18. pii: bjophthalmol-2015-306683. 
27. Kostev K, Jockwig A, Hallwachs A, Rathmann W. Prevalence and risk factors of neuropathy in newly diagnosed type 2 diabetes in primary care practices: a retrospective database analysis in Germany and U.K. Prim Care Diabetes. 2014 Oct;8(3):250-5.

28. Looker HC, Nyangoma SO, Cromie D, Olson JA, Leese GP, Black M, Doig J, Lee N, Lindsay RS, McKnight JA, Morris AD, Philip S, Sattar N, Wild SH, Colhoun HM; Scottish Diabetic Retinopathy Screening Collaborative; Scottish Diabetes Research Network Epidemiology Group. Diabetic retinopathy at diagnosis of type 2 diabetes in Scotland. Diabetologia. 2012 Sep;55(9):2335-42.

29. Kostev V and Rathmann W. Diabetic retinopathy at diagnosis of type 2 diabetes in the UK: a database analysis. Diabetología 2013;56:109-11.

30. Kohner EM, Aldington SJ, Stratton IM, Manley SE, Holman RR, Matthews DR, Turner RC. United Kingdom Prospective Diabetes Study, 30: Diabetic retinopathy at diagnosis of noninsulindependent diabetes mellitus and associated risk factors. Arch Ophthalmol 1998;116:297-303

31. Ding J, Wong TY. Current epidemiology of diabetic retinopathy and diabetic macular edema. Curr Diab Rep. 2012 Aug;12(4):346-54.

32. Gregg EW, Li Y, Wang J, Burrows NR, Ali MK, Rolka D, Williams DE, Geiss L. Changes in diabetes-related complications in the United States, 1990-2010. N Engl J Med. 2014 Apr 17;370(16):1514-23. 